\title{
Experimental study of CFST column to steel beam bolted connection with curved end-plates
}

\author{
Andrej Mudrov ${ }^{1}$, Antanas Šapalas ${ }^{2}$, Gintas Šaučiuvènas ${ }^{3}$ \\ Department of Steel and Composite Structures, Vilnius Gediminas Technical University, Vilnius, Lithuania \\ E-mail: 'andrej.mudrov@vgtu.lt (corresponding author)
}

\begin{abstract}
This paper presents results of experimental study of a bolted column-beam connection with an extended curved end-plate joining steel beam and a hollow core Concrete-Filled Steel Tube (CFST). Column concrete hollow core was formed by centrifugal casting process that allowed decreasing porosity, increasing homogeneity and strength of the concrete. It was expected that strength and stiffness of the joint would be significantly affected by spalling of the concrete core due to transverse action, which would limit rotation of the joint and bearing capacity of the column. However, the concrete hollow core had no prominent signs of fracture - bending strength of the joint was determined by punching shear of the steel tube wall. Further result analysis has shown that, in reference to Eurocode 3, the joint may be classified as semi-rigid and that non-uniform initial contact between the end-plates and the column can reduce stiffness of the joint. In addition to this, it has been found that the analytical Eurocode component method is in close agreement with the attained test results, but its feasibility should be validated against additional tests with other failure modes.
\end{abstract}

Keywords: concrete technologies, composite and layered structures, steel and aluminium structures.

\section{Introduction}

The circular concrete-filled steel tubular (CFST) columns are characteristic of ductility, strength and a wide range of possibilities enabling incorporation of advanced materials and techniques, like spun concrete, thus making them the go-to solution when the traditional design fails. Centrifugal casting enables decreasing porosity of the concrete, increasing its homogeneity and strength, while minimizing self-weight by forming an annular cross section (Kliukas, Kudzys, \& Vadlūga, 2010). The study has shown (Kvedaras \& Sapalas, 1999) that, in case of a conventional multistorey building, in a non-seismic area, a mixed framework with hollow core CFST columns could reduce usage of steel and concrete by half in comparison to a regular reinforced concrete frame. The economic effect would increase even more if CFST higher fire resistance was considered. However, despite these facts, the advantages of CFST are still wildly unexploited.

The main reason of limited prevalence of CFST is the lack of design guidelines on cost-effective and constructionefficient joints. The existing most convenient ways of connecting a steel beam to a column tube, like welding the beam directly to the column, diaphragms and through beams, require extensive amount of on-site welding with time consuming quality control thus making them economically not feasible. According to Chen, Qin, and Wang (2015), bolted connections can provide similar or even more favourable behaviour under various load conditions. As such, bolted end-plate connections could be considered as a good alternative to their fully welded counterparts.

Bolted connections to CFST can be grouped into two general categories (Alostaz \& Schneider, 1996): connections that load only the wall of the tube, and connections which penetrate the steel shell with components that are then imbedded in the concrete core. It is widely acknowledged that the first direct force transfer approach limits the connection moment capacity due to flexibility of Hollow Steel Section (HSS) wall (Barnett, Tizani, \& Nethercot, 2000) and also, as Chen et al. (2015) cited, it may result in separation of the steel tube from the concrete core and possibly compromise the confinement of the concrete due to additional stress on the shell. Nevertheless, column-beam connections to CFST with bolted end-plates are broadly studied. Wang, Han, and Uy (2009) tested flush-end plate connections with high strength blind bolts. Thai et al. performed a finite element modelling (Thai \& Uy, 2015a), an analytical (Thai \& Uy, 2015b) and experimental study (Thai, Uy, Yamesri, \& Aslani, 2017) of composite beams with flushed and extended end-plates. Tao, Hassan, Song, and Han (2017) tested composite beam connections to stainless steel columns and made the same conclusions as Thai et al.: that, due to curved end-plates, joints with concrete-filled circular hollow

(C) 2019 Authors. Published by VGTU Press. This is an open-access article distributed under the terms of the Creative Commons Attribution (http://creativecommons.org/licenses/by/4.0/) License, which permits unrestricted use, distribution, and reproduction in any medium, provided the original author and source are credited. 
sections (CHS) could have higher initial stiffness and flexural resistance in comparison to joints with a concrete-filled Square Hollow Sections. As for hollow CFST columns, literature is limited only to member behaviour with no information on joints.

This paper presents results of an experimental investigation of joints between a steel beam and a circular hollow core CFST column. The main objective of this study was to determine the failure modes of bolted connection by way of an experiment and compare the results with existing analytical Eurocode models (European Committee for Standardization, 2005).

\section{Specimens and test set-up}

A single-layer concrete hollow core was formed by spinning a CHS $219 \times 6 \mathrm{~mm}$ tube in the lathe. The centrifuging process was based on the work of Kuranovas et al. (Kuranovas \& Kvedaras, 2007) and was divided in three phases with different velocities: distribution of wet concrete at $160 \mathrm{rev} / \mathrm{min}$; formation of a concrete core at $260 \mathrm{rev} / \mathrm{min}$; compaction of concrete at $426 \mathrm{rev} / \mathrm{min}$. A time period of 15 minutes was taken for proper press out of excess water in compaction phase. Distribution and formation phases lasted for overall $4 \mathrm{~min}$. In result, average $21.6 \mathrm{~mm}$ concrete core thickness with variation of $3.8 \%$ was attained.

Four connections were tested by monotonic loading under $10 \mathrm{MN}$ capacity test machine. Loading was divided into two steps. Initial $500 \mathrm{kN}$ force in concrete hollow core column was introduced and manually maintained to be constant during the first step. This force was set to be equal to one third of the bearing capacity of the column. During the second loading step, the equal and opposite moments were induced by manually controlled hydraulic cylinders (Figure 1). Vertical and horizontal displacements were measured by LVDTs.
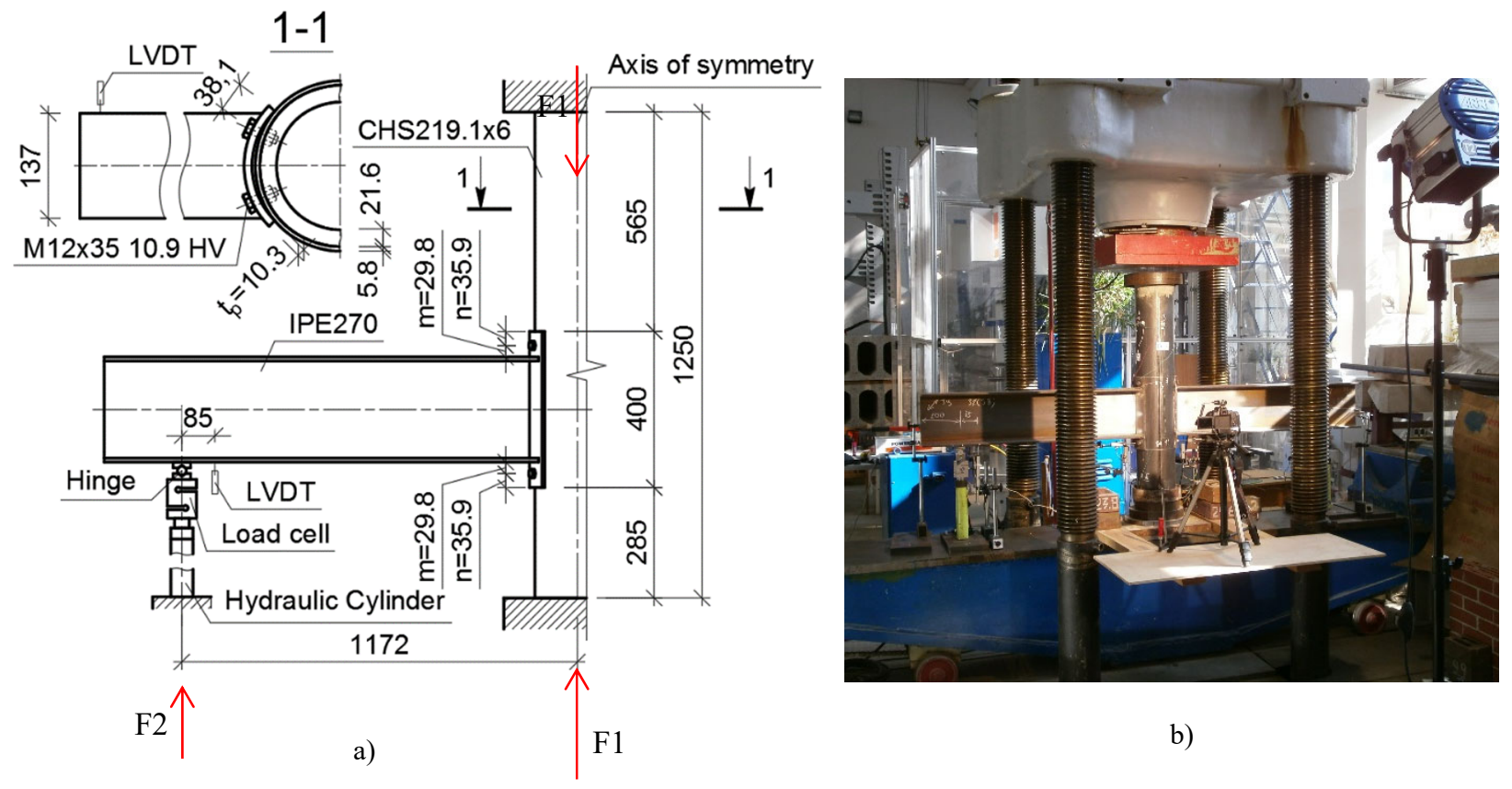

b)

Figure 1. Test set-up: a) plan view; b) test stand

A concrete mix was designed for approximate $30 \mathrm{MPa}$ compressive $(10 \times 10 \times 10 \mathrm{~cm})$ cube strength of plain concrete in 28 days (Table 1). Its main aggregate was sand with loose bulk density of $1.638 \mathrm{~g} / \mathrm{cm}^{3}$ and particle density of $2.65 \mathrm{~g} / \mathrm{cm}^{3}$. CEMII/A-LL 42.5N Portland cement with standard consistence of 0.2746 was used for the binder. The recommended concrete slump of $100 \mathrm{~mm}$ (Kuranovas \& Kvedaras, 2007) was achieved with approximate 0.49 initial water/cement ratio in which sand moisture content was not taken into account.

Curved end-plates were manufactured of same diameter but thicker, seamless CHS $219 \times 10$ pipe, which was cut into four equal pieces. Due to this, contact between the end-plate and the column wall was not uniform: only the sides of the end-plates were in contact with the column. An initial gap exceeding $2.0 \mathrm{~mm}$ was ascertained in the middle of the end-plates (Figure 2). 
Mudrov, A.; Šapalas, A.; Šaučiuvenas, G. 2019. Experimental study of CFST column to steel beam bolted connection with curved end-plates

Table 1. Mechanical and physical properties of the plain $10 \times 10 \times 10 \mathrm{~cm}$ concrete cubes

\begin{tabular}{|c|c|c|c|c|c|}
\hline \multirow{2}{*}{ No } & \multirow{2}{*}{ Specimen (number of tests) } & \multicolumn{2}{|c|}{ Compressive cube strength $f_{c}, \mathrm{MPa}$} & \multicolumn{2}{|c|}{ Density $\rho, \mathrm{kg} / \mathrm{m}^{3}$} \\
\cline { 3 - 6 } & & Average & St. dev. & Average & St. dev. \\
\hline 1 & IA (3) & 39.4 & 3.2 & 2180 & 4.5 \\
\hline 2 & IIA (3) & 41.7 & 1.6 & 2193 & 7.8 \\
\hline 3 & IIIA (6) & 49.6 & 2.3 & 2217 & 8.7 \\
\hline 4 & IVA (4) & 43.6 & 1.3 & 2218 & 13.1 \\
\hline
\end{tabular}

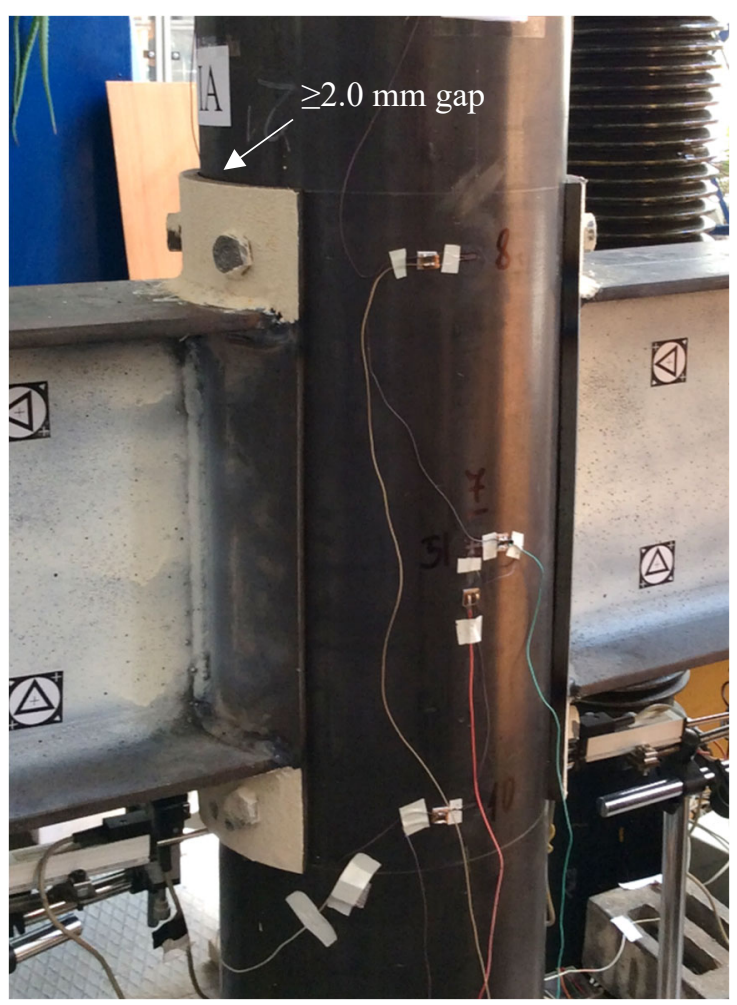

Figure 2. Initial gap

Prior to centrifuging, the end-plates were bolted to a cold-formed column with four high-strength M12 HV 10.9 class bolts which were then removed after the concrete had set. Centrifuging column with mounted end-plates enabled precise imbed of the nuts for the correct preassembly of the joints. When the concrete had set, the end-plates were dismantled and IPE 270 beams were welded to them. The average throat thickness of the weld was $4.44 \mathrm{~mm}$. All removed bolts had damaged threads due to concrete contamination and had to be repaired. Mechanical and physical steel properties (see Table 2) were obtained by testing the standardized test pieces. The test specimens were assembled without initial preloading of the bolts.

Table 2. The mechanical and physical properties of steel and fasteners

\begin{tabular}{|l|c|c|c|c|c|c|}
\hline \multirow{2}{*}{ Index } & \multicolumn{2}{|c|}{$\begin{array}{c}\text { End-plate steel P355N } \\
(4 \text { tests })\end{array}$} & \multicolumn{2}{c|}{$\begin{array}{c}\text { Steel of CHS S235 } \\
\text { (4 tests) }\end{array}$} & \multicolumn{2}{c|}{$\begin{array}{c}\text { High-strength bolts } \\
\text { M12x35 10.9 HV (4 tests) }\end{array}$} \\
\cline { 2 - 7 } & Average & $\begin{array}{c}\text { Standard } \\
\text { deviation }\end{array}$ & Average & $\begin{array}{c}\text { Standard } \\
\text { deviation }\end{array}$ & \multicolumn{2}{|c|}{$\begin{array}{c}\text { Average } \\
\text { Standard } \\
\text { deviation }\end{array}$} \\
\hline Yield strength $f_{y}, f_{y b}$ & $389,8 \mathrm{MPa}$ & $4.30 \mathrm{MPa}$ & $318.8 \mathrm{MPa}$ & $21.52 \mathrm{MPa}$ & - & - \\
\hline Ultimate strength $f_{u}, f_{u b}$ & $551.9 \mathrm{MPa}$ & $2.83 \mathrm{MPa}$ & $419.6 \mathrm{MPa}$ & $11.28 \mathrm{MPa}$ & $1147 \mathrm{MPa}$ & $14.31 \mathrm{MPa}$ \\
\hline Modulus of elasticity $E$ & $280.2 \mathrm{GPa}$ & $16.10 \mathrm{GPa}$ & $151.6 \mathrm{GPa}$ & $5.63 \mathrm{GPa}$ & - & - \\
\hline
\end{tabular}




\section{Test results and observations}

The tests were terminated when a fracture of the bolts occurred in either side of the connection. The bolt fracture was located near the unthreaded portion of the bolt shank (Figure 3). In comparison to the tensile tests of the individual fastener assemblies, bolts in the connections did not exhibit necking, which might be an indication of shear. Punching shear resistance of the column wall was exhausted prior to the bolt fracture (Figure 4), which was the main cause of premature yielding of the joints. A close examination of the internal concrete cores has shown that the main damage was spalling due to the bolt leaning in the tension zone (Figure 5) as the face of CHS deformed under load. No visible cracks in the concrete core were found.

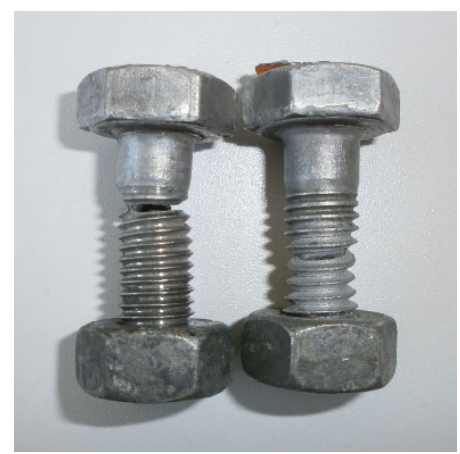

Figure 3. Fracture of the bolts: in the connection (on the left) and from individual bolt assembly tests (on the right)

The comparisons between analytical and experimentally derived moment - rotation curves are shown in Figure 6. The average experimental initial rotational stiffness of eight joints was $9313 \mathrm{kNm} / \mathrm{rad}$, with variation of $15 \%$. The average maximum experimental bending moment of $48.2 \mathrm{kNm}$, with variation of $3.5 \%$, and maximum average rotation capacity of 3.86 mrad with $8.76 \%$ variation were obtained.

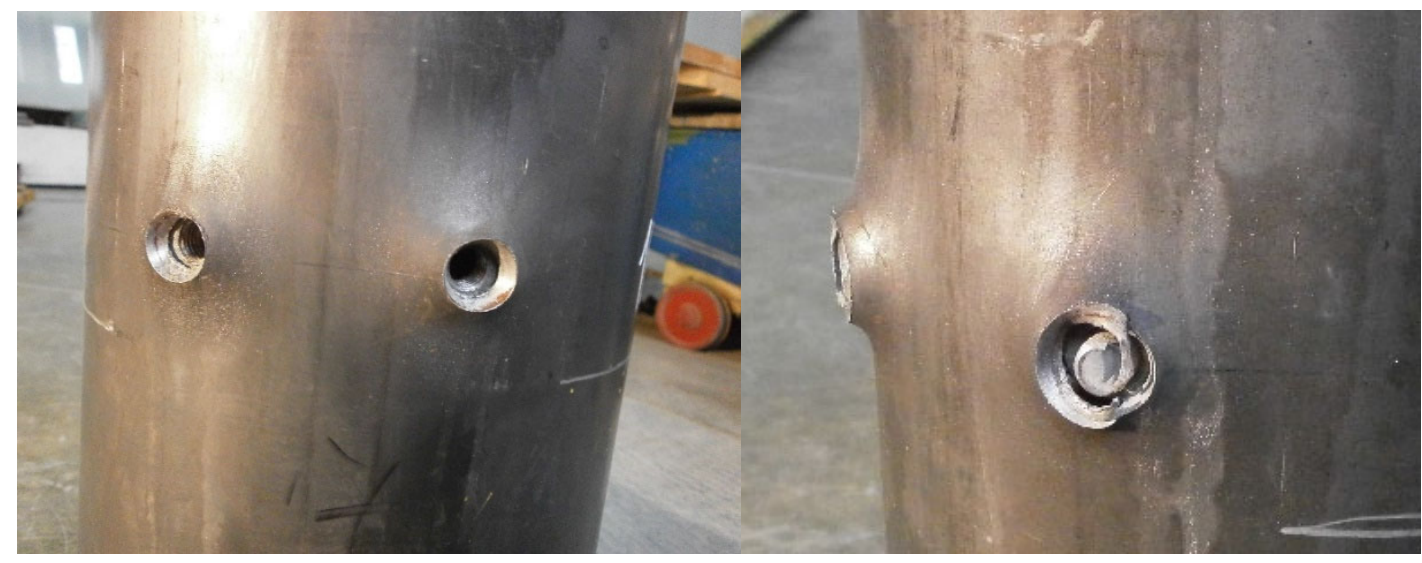

Figure 4. Punching shear of the CHS wall surface
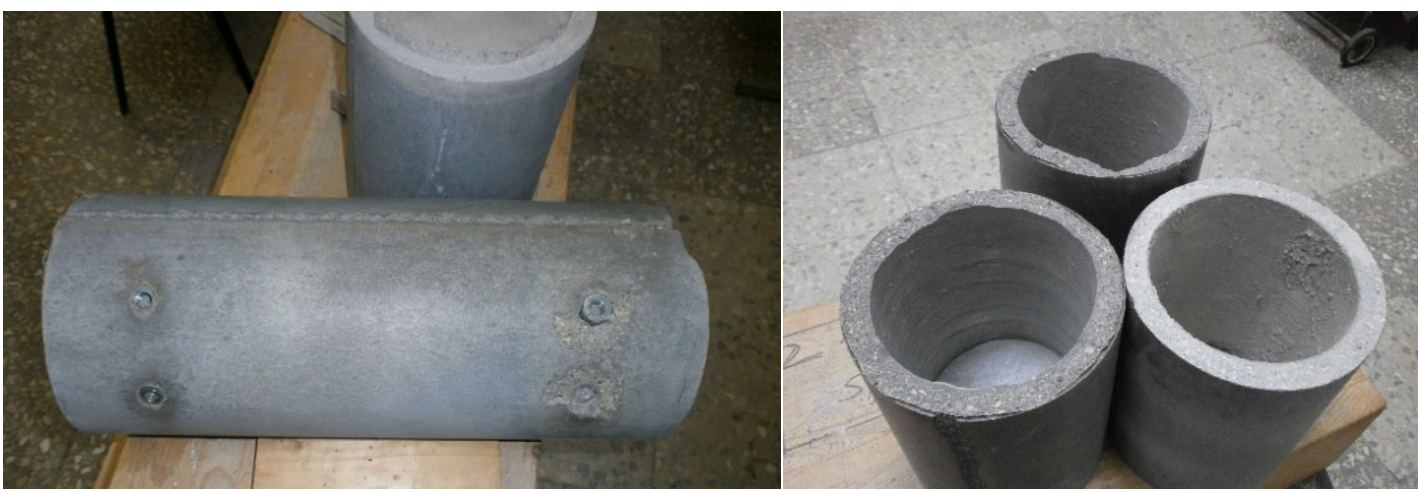

Figure 5. Cut away middle segments of the composite column without the steel cover 


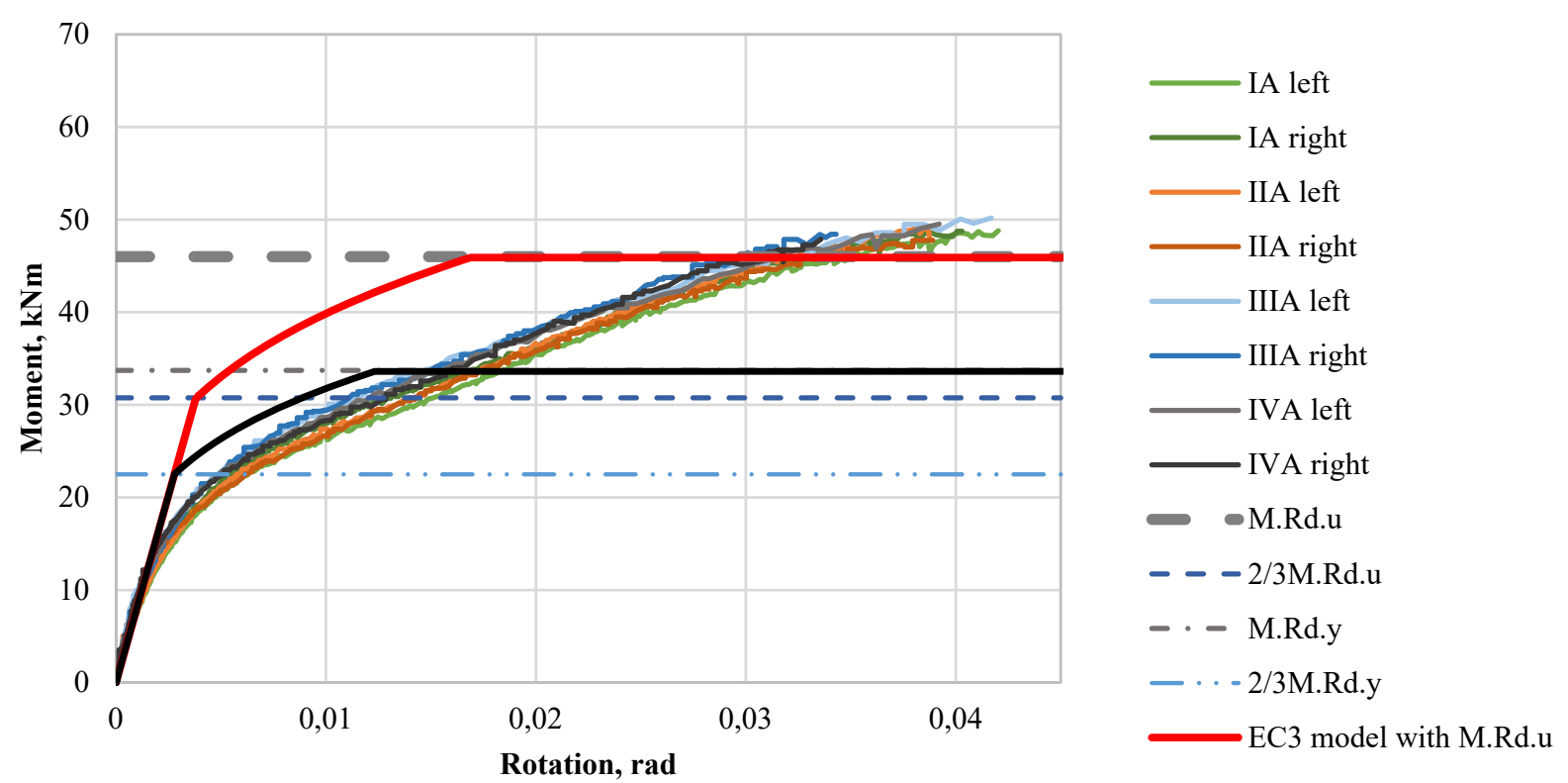

Figure 6. Comparisons between the experimental tests and the Eurocode model

The ultimate theoretical moment capacity of the joints was calculated by using the Eurocode 3 model of Equivalent T-stub in which resistance of the bolts was set to be a minimal failure load of the bolt in the tension or punching shear of the column wall. The effective length of the curved end-plate was simplified to a mechanism of corner yielding of the flat plate $\left(2 \mathrm{~m}+0.625 \mathrm{e}+\mathrm{e}_{1}\right)$. This pattern was chosen based on observation that prying forces tend to develop only on the corners of the end-plates, which was evident from the scratch marks on the column surface. Furthermore, the end-plates were covered with chalk paint in order to monitor plastic deformations (Figure 7), which showed that plastic deformations were exclusively present in the compression zone of the end-plates due to closing of the initial gap.

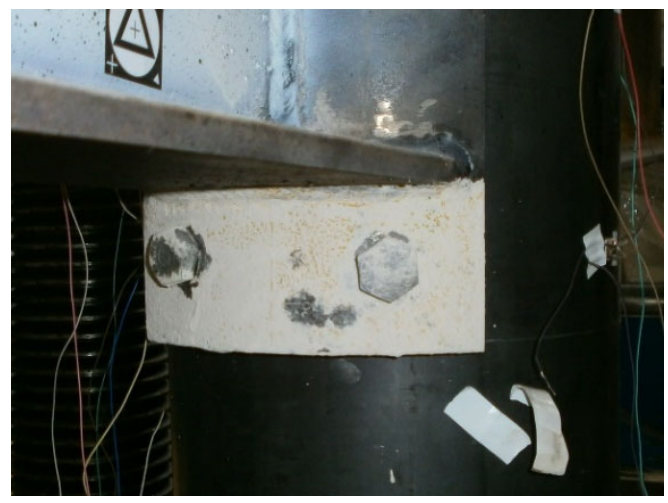

a)

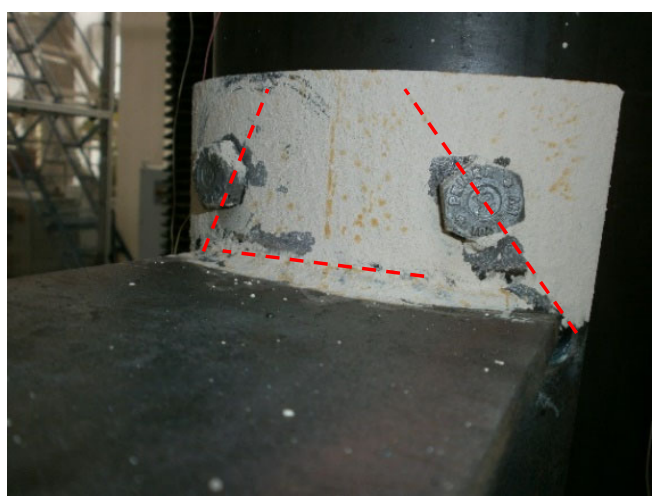

b)

Figure 7. Deformations of the end-plate: a) no plastic deformations in the tension zone; b) plastic deformations in the compression zone

Theoretical initial rotational stiffness of $8729 \mathrm{kNm} / \mathrm{rad}$ was calculated by using the Eurocode component model with minor adjustments (see Eq. (1)): a coefficient of 0.9, which accounts for prying forces, was emitted for end-plate in tension zone $\left(k_{e p b}\right)$ and only a half of effective T-stub length was used; for part in compression, stiffness coefficient of end-plate in bending under compression was introduced with effective length of corner yielding mechanism (assumption of equal T-stub length in tension and compression was made); components of the column wall in compression and in tension were considered to have infinite stiffness. With these adjustments, the theoretical stiffness is lower than experimental one by only $6.3 \%$.

$$
S_{j . i n i}=\frac{z^{2}}{\frac{1}{E_{p l}}\left[\frac{1}{k_{e p b}}+\frac{1}{k_{e n b c}}\right]+\frac{1}{E_{b}}\left[\frac{1}{k_{b}}\right]}=\frac{z^{2}}{\frac{1}{E_{p l}}\left[\frac{2 m^{3}}{l_{\text {eff }} \cdot t^{3}}+\frac{(m+n)^{3}}{l_{\text {eff }} \cdot t^{3}}\right]+\frac{1}{E_{b}}\left[\frac{L_{b}}{2 A_{s}}\right]},
$$


where: $S_{j . i n i}$ - initial stiffness; $z$ - lever arm; $E_{p l}$ - modulus of elasticity of the end-plate; $E_{b}$ - modulus of elasticity of the bolts; $k_{b t f}$ - elastic stiffness of the end-plate in bending; $k_{e p b c}$ - elastic stiffness of the end-plate in bending under compression; $k_{b}$ - elastic stiffness of the bolts in tension; $A_{s}$ - stress area of the bolt; $L_{b}-$ grip length of the bolt; $t$ - thickness of the end-plate; $l_{\text {eff }}$ - effective T-stub length.

In accordance with Eurocode, this joint may be classified as a semi-rigid one based on its rotational stiffness. To meet the classification boundaries of a rigid joint, the length of IPE 270 beam in the braced frame should exceed $10.44 \mathrm{~m}$. On the other hand, the beam length should be less than $0.65 \mathrm{~m}$ in order for it to be classified as a nominally pinned. In both of these cases such IPE270 beam lengths are impractical.

By comparing the theoretical moment resistance of the joints to the theoretical bending resistance of the beam (which is $114 \mathrm{kNm}$ ), this joint may be classified as a partial strength. But it should be noted, that when bolts punching shear resistance is calculated with the ultimate steel strength, as it is suggested by the Eurocode, experiment has shown, that the theoretical Eurocode 3 model overestimates plastic resistance (Figure 6). When the yield strength is used instead, the Eurocode model tends to predict plastic resistance more accurately, with greater rotation capacity. Therefore, the use of yield strength is suggested to avoid the brittle fracture.

\section{Conclusions}

- A non-uniform contact between the end-plates and the column may have an impact on the behaviour of the joint. When the gap in the compression zone of the end-plate is present, its closing can cause plastic deformations in the flange and reduce initial stiffness of the joint.

- The failure mode of the bolted connection between the steel beam and the hollow core CFST column was the same as the one reported in literature for columns with solid core, which can be attributed to limited moment capacity due to punching shear failure of the CHS wall. The concrete hollow core was damaged only with local spalling, which was the result of the bolt leaning as the walls of CHS deformed under load.

- Calculations of punching shear resistance with using ultimate steel strength overestimates plastic capacity of the joint and can lead to a brittle fracture. By using yield strength Eurocode 3 model was found to accurately predict plastic resistance without limiting the rotation capacity in the case of column wall failure. For other failure modes additional research is required to validate Eurocode model.

- In accordance with the Eurocode, this connection may be classified as a semi-rigid and by comparing design moment resistances - partial strength.

\section{References}

Alostaz, Y. M., \& Schneider, S. P. (1996). Connections to concrete-filled steel tubes. University of Illinois Engineering Experiment Station. College of Engineering. University of Illinois at Urbana-Champaign.

Barnett, T., Tizani, W., \& Nethercot, D. A. (2000). Blind bolted moment resisting connections to structural hollow sections. In Conference Connections in Steel Structures IV: Steel Connections in the New Millennium. Roanoke, Virginia, USA.

Chen, Z., Qin, Y., \& Wang, X. (2015). Development of connections to concrete-filled rectangular tubular columns. Advanced Steel Construction, 11(4), 408-426. https://doi.org/10.18057/IJASC.2015.11.4.1

European Committee for Standardization. (2005). Eurocode 3: Design of steel structures - Part 1-8: Design of joints (EN 1993-18:2005/AC:2009).

Kliukas, R., Kudzys, A., \& Vadlūga, R. (2010). The quasi-ductile resistance of compressed spun concrete beam-columns. Journal of Civil Engineering and Management, 16(2), 189-196. https://doi.org/10.3846/jcem.2010.20

Kuranovas, A., \& Kvedaras, A. K. (2007). Centrifugally manufactured hollow concrete - filled steel tubular columns. Journal of Civil Engineering and Management, 13(4), 297-306. https://doi.org/10.3846/13923730.2007.9636450

Kvedaras, A., \& Sapalas, A. (1999). Research and practice of concrete-filled steel tubes in Lithuania. Journal of Constructional Steel Research, 49(2), 197-212. https://doi.org/10.1016/S0143-974X(98)00218-1

Tao, Z., Hassan, M. K., Song, T.-Y., \& Han, L.-H. (2017). Experimental study on blind bolted connections to concrete-filled stainless steel columns. Journal of Constructional Steel Research, 128, 825-838. https://doi.org/10.1016/j.jcsr.2016.10.016

Thai, H.-T., \& Uy, B. (2015a). Finite element modelling of blind bolted composite joints. Journal of Constructional Steel Research, 112, 339-353. https://doi.org/10.1016/j.jcsr.2015.05.011

Thai, H. T., \& Uy, B. (2015b). Application of Eurocode 4 to blind bolted endplate composite joints with CFST columns. In 2015 World Congress on Advances in Structural Engineering and Mechanics (ASEM15). Incheon, Korea.

Thai, H.-T., Uy, B., Yamesri, \& Aslani, F. (2017). Behaviour of bolted endplate composite joints to square and circular CFST columns. Journal of Constructional Steel Research, 131, 68-82. https://doi.org/10.1016/j.jcsr.2016.12.022

Wang, J.-F., Han, L.-H., \& Uy, B. (2009). Behaviour of flush end plate joints to concrete-filled steel tubular columns. Journal of Constructional Steel Research, 65(4), 925-939. https://doi.org/10.1016/j.jcsr.2008.10.010 